\title{
The formation of mechanism of the large concretions found below high grade statabound Ni, Mo and V mineralization in Canada and China
}

\author{
Charlotte M. ERB ${ }^{1}$ AND DANIEL GREGory
}

1. charlotte.erb@mail.utoronto.ca, Earth Sciences Centre, 22

Russell street, Toronto ON

This thesis investigates high grade stratabound nickel, molybdenum and vanadium found in China and the Yukon, Canada. The mineralization of these metals occurs at the same horizon and can be traced for many kilometers. The three main models for formation of these types of deposits are through precipitations from seawater, SEDEX hydrothermal fluids, and petroleum-based transport of metals.

Current research focuses on the metal-rich horizon, however, large ( $>1$ meter) limestone concretions found below this horizon are of interest because of their unique association with the metals. These limestone concretions were formed 2 meters below the metal-rich horizon and can also be traced for kilometers, parallel to economic minerals. The fact that these concretions are always found at the same stratigraphic position below the metal-rich suggests a relation between them.

This study aims to obtain an understanding of the limestone concretions, an by inference, the formation of associated metal-rich horizon. Samples from the concretions found in China and Canada were used to obtain carbonate associated sulfide (CAS) isotope values from the rim and centre of the concretions. Following the CAS analysis, trace element and organic carbon lab data was used to ascertain how the concretions formed.

Determining how the limestone concretions associated with the high grade mineral horizons were formed, provides a more detailed understanding of these enigmatic deposits and may help develop better exploration strategies. 